\title{
Theoretical and methodological tools in designing and analysing mathematics teacher education practices
}

\author{
Despina Potari ${ }^{1}$
}

Published online: 1 July 2019

(c) Springer Nature B.V. 2019

In mathematics teacher education research, theoretical and methodological tools have been used in different ways. Theoretical frameworks and constructs have been used as a means for promoting teacher reflection (e.g. Mellon 2011); understanding mathematics teacher education practices and teacher professional learning (e.g. the use of zone theory to study teacher change by Goos 2013 or the use of boundary crossing to study teachers' learning in Cooper et al. 2019); or designing teacher education and professional development programs (e.g. the use of the notion of lessons as experiments in teacher preparation and professional development, e.g. Hiebert et al. 2003). Theoretical and methodological models either have been operationalized in the context of an empirical study or they have been transformed and/or developed as an outcome of the study.

The articles published in this issue address in different ways the role of the theoretical and methodological tools. The study of Land, Tyminski and Drake develops a coding scheme for analysing primary mathematics teachers' responses to children's mathematical thinking. Calligan, Axelsen, Pennicott, Addie, Galbraith and Woolcott propose a teacher education model aiming to promote prospective secondary school mathematics teachers' confidence and self-efficacy, while Wasserman, Weber, Fukawa-Conelly and McGuffey propose a model for teaching Real Analysis course for prospective and practicing teachers to improve mathematics teaching in upper secondary school. Finally, in the study of Prediger, Roesken-Winter and Leuders the proposed, theoretical model addresses existing research in the area of the professional development of mathematics teachers and facilitators. Below, I discuss the four articles providing more information about the way that the theoretical/methodological models have been used and what they offer at the empirical, theoretical and methodological level.

The article of Land, Tyminski and Drake reports a study in the area of teacher noticing of children's mathematical thinking, focusing on the way that teachers respond to it. Twenty practicing primary school teachers were interviewed, and they were asked to describe, interpret and respond to children's solution strategies in two arithmetic problems. The teachers had varied teaching experience and participation in professional development program based on Cognitive Guided Instruction (CGI). A coding scheme in the form of a rubric was developed to analyse teachers' responses consisting of four dimensions of the responding process: addressing the group or the individual students; considering the

Despina Potari

dpotari@math.uoa.gr

1 National and Kapodistrian University of Athens, Athens, Greece 
children's existing strategies; anticipating children's future strategies; and the responsive problem posing. The rubric is based on the three growth indicators of Jacobs et al. (2010), but the authors have elaborated and extended it in relation to their data. By using a scale from 1 to 3, the authors distinguished different degrees that the last three dimensions of the rubric applied in the teachers' responses. The results show that the participant teachers responded to children's thinking strategies in ways showing different levels of awareness of children's current and future strategies and different problem posing abilities being relevant to children's thinking. Looking also for possible relations between considering, anticipating and problem posing, they found that teachers who anticipated children's future strategies could also pose problems relevant to children's thinking. However, the nature of the findings shows that it is not possible to come to "solid" conclusions of some hierarchical relations between the three dimensions. We also see cases of teachers with long professional development and teaching experience who react differently in the way they respond to children's thinking. Looking for the underlying reasons of teachers' decisions could possibly provide explanations of why the teachers respond to children's in certain ways. Concerning the contribution of the rubric scheme, it can be used both as a research and as a professional development tool.

The article of Calligan et al. addresses affective issues that need to be considered in mathematics teacher education. The authors focus their attention on the development of prospective mathematics teachers' confidence, self-efficacy and emotional states in teaching mathematical modelling at secondary school classrooms. This development was supported through a particularly designed mathematics teacher education program adopting a specific teacher education strategy, the Enhancement-Lesson-Reflection process (ELR). ELR emphasized conceptual learning and problem solving, student focused learning and multiple repeated sessions that focus on learning (enhancement), lesson planning, teaching, feedback and reflection. Adopting a mixed study approach with a range of research instruments (confidence and competence checklist survey, a self-report measure of positive and negative affect, a post-teaching session recorded debrief and unstructured focus group interviews), the authors study the impact of the ELR teacher education strategy in nine prospective teachers' confidence, self-efficacy and emotions in teaching mathematical modelling. The results show that confidence and self-efficacy of prospective teachers improved through their participation in the program and that prospective teacher valued more the enhancement sessions, while they worked on modelling problems and the feedback-reflection session after teaching modelling in a school classroom. The study does not come to conclusions about positive or negative emotional states as the result of prospective teachers' engagement with the ELR teacher education strategy. Many studies have shown that the cycle of doing mathematics, planning, enacting and reflecting on lessons at school is an important teacher education strategy for prospective teachers' learning (e.g. Rasmussen 2016). The study of Calligan et al. strengthens the importance of this cycle in mathematics teacher education by going beyond the cognitive dimension and providing evidence of its role in improving prospective teachers' confidence and self-efficacy in teaching mathematical modelling, a rather unfamiliar area to them from their school years.

Wasserman et al. address the question whether an advanced mathematics course, in this case in Real Analysis, is helpful for a prospective and practicing secondary mathematics teacher in teaching. The authors offer an alternative way to teaching Real Analysis for teachers that links advanced mathematics, secondary mathematics and teaching secondary mathematics. They developed 12 modules in Real Analysis that connect advanced mathematics and secondary mathematics and teaching in two ways: build-up from teaching at school to advanced mathematics and stepping down from advanced mathematics to 
secondary school teaching. The authors evaluate the impact of one of the modules focusing on the mathematical practice of derivative proof as "attending to scope" on the mathematics teaching that the participant teachers enacted in their classrooms. The analysis of teaching showed that the teachers used the "attending to scope" mathematical practice in several instances of teaching. From the analysis of the interviews with the teachers, these instances often were drawn on the designed Real Analysis course. The findings of the study challenge existing research that university advanced courses are not relevant to teachers and show that courses that manage to link, academic mathematics with school mathematics and mathematics teaching can contribute to the development of mathematical practices closer to "doing mathematics". The study also offers methodological ways of how to link mathematics teacher education practices with teaching.

Prediger, Roesken-Winter and Leuders offer a theoretical model to discuss research in mathematics teacher education for teachers and facilitators. This is a three-layer model using as a basis the didactical tetrahedron for describing classroom teaching, its extension to capture professional development of teachers and finally professional development of facilitators. The authors introduce the constructs of three research strategies, the lifting, nested and unpacking to show certain links between the three layers in existing research on professional development of teachers and facilitators. These strategies are illustrated through research examples and the interplay of them in terms of design features of the professional development contexts and the research questions that the studies address is evidenced through the analysis of two studies, one in professional development of teachers and the other of facilitators. Through this analysis, the authors address issues related to generic- and content-specific professional development, the complexity of mathematics teaching and professional development contexts, the relation between classroom tasks and PD tasks and the multi-faceted nature of required knowledge of facilitators. Finally, the authors through an example from their own research illustrate how their model can be used to pose research questions useful for PD facilitators. The developed model contributes to a systematization of the existing research related to professional development of teachers and facilitators and helps researchers to identify open research questions that can be addressed in the area of professional development. It also offers ways of designing and evaluating professional development contexts that can link mathematics learning and teaching in the classroom, professional development of teachers and facilitators in different ways.

All the contributions in this issue transform and develop theoretical and methodological tools for research and practice in mathematics teacher education. These tools have emerged in specific national and educational contexts and aim to be generalized in other contexts. However, further research is needed to see whether the models suggested for designing and researching mathematics teacher education and professional development can be transformed in other settings and what forms of adaptations they need.

\section{References}

Cooper, J., Olsher, S., \& Yerushalmy, M. (2019). Didactic metadata informing teachers' selection of learning resources: Boundary crossing in professional development. Journal of Mathematics Teacher Education. https://doi.org/10.1007/s10857-019-09428-1.

Goos, M. (2013). Sociocultural perspectives in research on and with mathematics teachers: A zone theory approach. ZDM Mathematics Education, 45(4), 521-533.

Hiebert, J., Morris, A. K., \& Glass, B. (2003). Learning to learn to teach: An "experiment" model for teaching and teacher preparation in mathematics. Journal of Mathematics Teacher Education, 6, 201-222. 
Jacobs, V. R., Lamb, L., \& Philipp, R. A. (2010). Professional noticing of children's mathematical thinking. Journal for Research in Mathematics Education, 41(2), 169-202.

Mellon, M. (2011). The influence of theoretical tools on teachers' orientation to notice and classroom practice: A case study. Journal of Mathematics Teacher Education, 14, 269-284.

Rasmussen, K. (2016). Lesson study in prospective mathematics teacher education: Didactic and paradidactic technology in the post-lesson reflection. Journal of Mathematics Teacher Education, 19, 301-324.

Publisher's Note Springer Nature remains neutral with regard to jurisdictional claims in published maps and institutional affiliations. 